\title{
Single-crystal silicon coimplanted by helium and hydrogen: Evolution of decorated vacancylike defects with thermal treatments
}

\author{
C. Macchi,* S. Mariazzi, G. P. Karwasz, ${ }^{\dagger}$ and R. S. Brusa ${ }^{\ddagger}$ \\ Dipartimento di Fisica, Università di Trento, I-38057 Povo, Trento, Italy \\ P. Folegati \\ Dipartimento di Fisica, Politecnico di Milano, Piazza L. da Vinci 3220133 Milano, Italy
}

\begin{abstract}
S. Frabboni and G. Ottaviani
INFM-National Research Center on Nanostructures and bioSystems at Surfaces-S3 and Dipartimento di Fisica, Università di Modena e Reggio Emilia, via dei Campi 213/A-41100 Modena, Italy

(Received 29 April 2006; revised manuscript received 6 September 2006; published 29 November 2006)
\end{abstract}

\begin{abstract}
$\mathrm{Si}$-type (100) samples were coimplanted at room temperature with $\mathrm{He}^{+}$ions at $30 \mathrm{keV}$ with a dose of 1 $\times 10^{16}$ ions $/ \mathrm{cm}^{2}$ and successively with $\mathrm{H}^{+}$ions at $24 \mathrm{keV}$ with a dose of $1 \times 10^{16}$ ions $/ \mathrm{cm}^{2}$. A series of samples was thermally treated for $2 \mathrm{~h}$ from 100 to $900{ }^{\circ} \mathrm{C}$ at $100{ }^{\circ} \mathrm{C}$ steps to study the evolution of pointlike and extended defects by two complementary techniques: positron Doppler broadening spectroscopy and transmission electron microscopy. Depth profiling the samples with a positron beam led to the identification of five different traps and the evolution of their profile distributions with thermal treatments. The positron traps were identified as decorated vacancy clusters of different sizes. Their decoration by implanted ions and in some case by oxygen was probed by coincidence Doppler broadening spectroscopy. Up to $300{ }^{\circ} \mathrm{C}$ annealing temperature positrons probe three distributions of different decorated defects covering regions of the sample down to 400-450 nm. Starting from $300{ }^{\circ} \mathrm{C}$ annealing temperature no defects were revealed by positrons in the region next to the peak of the implanted ions distributions positioned around $280 \mathrm{~nm}$, where extended defects are expected; this indicates complete filling of the defects by $\mathrm{H}$ and He. From 300 to $600{ }^{\circ} \mathrm{C}$ decorated vacancy clusters of different sizes appear progressively in the region below $280 \mathrm{~nm}$, with a distribution moving deeper into the sample. Comparison with previous measurements on He-implanted samples points out the chemical action of $\mathrm{H}$. Hydrogen atoms interact with the previous damage by He, producing more stabilized vacancylike defects distributed through the damage region of the sample. Electron microscopy shows the transformation of the extended defects from platelets to blisters and cavities.
\end{abstract}

DOI: 10.1103/PhysRevB.74.174120

PACS number(s): 78.70.Bj, 71.60.+z, 61.72.Ji, 61.72.Qq

\section{INTRODUCTION}

The study of the effects induced in semiconductors by implantation with light ions, helium, and hydrogen, is of great technological and scientific importance. $\mathrm{H}_{2}$ (the more stable hydrogen configuration in perfect $\mathrm{Si}$ ) and $\mathrm{He}$ in $c$-Si occupy the same interstitial $T_{d}$ site, $, 1,2$ have the same solution enthalpy $(0.8 \mathrm{eV})$ and very similar migration energies (1.0 and $0.8-1.0 \mathrm{eV}$, respectively). ${ }^{2}$ Beyond these similarities, $\mathrm{H}$ and $\mathrm{He}$ have a very different behavior: $\mathrm{H}$ in $\mathrm{Si}$ is extremely reactive with all kind of defects, impurities, surfaces, and saturates broken chemical bonds; on the contrary $\mathrm{He}$, does not manifest chemical reactivity. $\mathrm{H}$ is known to passivate shallow and deep-level defects, but it can also introduce electronic deep levels: in both cases $\mathrm{H}$ has a strong influence on the electrical properties of $\mathrm{Si}^{3,}{ }^{3,4} \mathrm{H}$ can also promote the formation of extended defects as platelets. He, on the other side, tends to agglomerate in Si forming clusters of different sizes and also causes extended defects ${ }^{5}$ originate. $\mathrm{H}$ and $\mathrm{He}$, singly implanted in $\mathrm{Si}$, behave in a complex way as a function of the implanted dose and of the thermal treatments. The dynamics and the modifications induced by the thermal treatments depend on the local concentration of these atoms and involve the helium-helium, the hydrogen-hydrogen interaction, and the $\mathrm{He}$ and $\mathrm{H}$ interaction with the vacancies pro- duced by the implantation process. If the implanted dose is equal or higher than $2 \times 10^{16}$ atoms $/ \mathrm{cm}^{2}$, and the samples are thermally treated at temperatures equal or higher than $900{ }^{\circ} \mathrm{C}$, $\mathrm{He}$ and $\mathrm{H}$ (and $\mathrm{H}_{2}$ ) form bubbles and then outdiffuse living nanocavities in the materials. ${ }^{2,6}$ Recently it has been discovered that the internal surfaces of the formed nanocavities are clean. ${ }^{7,8}$ For technical applications, clean nanocavities in $\mathrm{Si}$ are used as gettering centers for several heavy metals. ${ }^{9}$ Increasing the $\mathrm{H}$ and $\mathrm{He}$ ion dose implantation, blistering, and exfoliation can occur: these phenomena have found practical applications in the wafer splitting technology. ${ }^{10-12}$ The phenomena that cause the bubbles and cavities formation are several and they involve the implanted species as well as vacancies, interstitials, impurities, and dopants. $^{2}$

Depth profiling positron annihilation spectroscopy (DPPAS) was successfully used to study the open volume defects in $\mathrm{H}^{13-15}$ and $\mathrm{He}^{16-20}$ implanted crystalline silicon $(c-\mathrm{Si})$. DP-PAS is a powerful nondestructive tool for the characterization of the open volume defects from vacancies to nanovoids. It is possible to investigate the first layers of the sample from few nanometers down to some microns controlling the probed depth by varying the incident positron beam energy. DP-PAS can be carried out with different techniques: Doppler broadening spectroscopy (DBS), coincidence Dop- 
pler broadening (CDB), positron annihilation lifetime spectroscopy (PALS), and 2-3 $\gamma$ ratio of positronium ( $3 \gamma$-PAS). ${ }^{21}$ DBS is well indicated to extract defect profiles and types of defects, CDB to investigate the chemical environment of the open volume defects, PALS to give information on the types and on the size of the open volumes, $3 \gamma$-PAS to study porosities in insulating materials.

In the previous papers, Refs. 13-20, it was pointed out that DP-PAS allows to identify the open volume defects and to study their interaction with the implanted species ( $\mathrm{H}$ and $\mathrm{He}$ ) vs the implantation ion dose, implantation energy, and thermal treatments. Vacancies are known to diffuse easily in $\mathrm{Si}^{22}$ to recombine with self-interstitials, to diffuse out from $\mathrm{Si}$, to form clusters and complexes of different dimensions depending on the thermal treatments.

In the region below the peak of the ion implanted distribution divacancies stabilized by $\mathrm{H}$ were detected by DP-PAS. ${ }^{13-15}$ At low ion dose and low implantation energy, $\mathrm{H}$ was found mainly to passivate vacancylike defects and open volumes saturating the Si dangling bonds next to the peak of the ion implantation distribution. ${ }^{13,14}$ Differently, at low ion dose and high implantation energies the passivation was only partial and DBS ${ }^{13}$ and PALS ${ }^{15}$ detected also $\mathrm{H}$ open volumes decorated defects. Thermal treatments produced the appearance of larger $\mathrm{H}$ decorated vacancy clusters and voids up to $700{ }^{\circ} \mathrm{C} .{ }^{15}$

The evolution of open volume defects (from vacancies to vacancy clusters and then to cavities) with thermal treatments was followed by DBS in samples implanted with He at different implantation doses and energies. ${ }^{17-19}$ The combined use of DBS and other analytical techniques allowed to point out the role of $\mathrm{He}$ in decorating and stabilizing vacancies and vacancy clusters at the different annealing temperature. These results were confirmed by PALS measurements. ${ }^{20}$ $\mathrm{He}$, like $\mathrm{H}$, was found to be able to fully saturate open volumes, moreover $\mathrm{He}$ in $\mathrm{Si}$ tends to agglomerate forming bubbles with very high internal pressure. ${ }^{2}$ Positrons were found not to be trapped into bubbles or completely filled open volumes. As a matter of fact cavities produced by $\mathrm{He}$ implantation and annealing can be partially refilled by $\mathrm{H}$ or He implantation and as a consequence the positron annihilation signal decreases. ${ }^{16}$

Recently it has been found that coimplantation of $\mathrm{H}$ and $\mathrm{He}$ can produce, after heat treatments above $500-600{ }^{\circ} \mathrm{C}$, blistering and in some cases exfoliation of Si (Refs. 23-25) and GaAs (Ref. 26) for a thickness comparable to the projected range of the implanted ions. Coimplantation of $\mathrm{He}$ and $\mathrm{H}$ reduces, in comparison to single $\mathrm{H}$ implantation, the overall dose required to obtain $\mathrm{Si}$ exfoliation. ${ }^{23}$ This is due to the synergic effect of $\mathrm{He}$ and $\mathrm{H}$ and their mutual interaction with defects. $\mathrm{H}$ acts both chemically, by bond breaking and passivation of internal surfaces, and physically by coalescing in $\mathrm{H}_{2}$ increasing the internal pressure of the extended defects that it has produced. On the contrary $\mathrm{He}$ can only exert internal pressure by coalescing or diffusing into existing defects. The exfoliation process requires the formation of extended defects at a depth of the ion projected range, the filling of such defects with $\mathrm{He}$ and/or $\mathrm{H}_{2}$, their coalescence and finally their "explosion." Whether or not these defects are formed depends on the initial distribution and type of defects created by implantation and consequently is expected to depend on the order of implantation: $\mathrm{H}^{+}+\mathrm{He}^{+}$or $\mathrm{He}^{+}$ $+\mathrm{H}^{+} .{ }^{27}$ There are few works dealing with $\mathrm{Si}$ coimplanted by $\mathrm{He}^{+}+\mathrm{H}^{+}$(Refs. 24, 28, and 29) or $\mathrm{H}^{+}+\mathrm{He}^{+} .{ }^{23,30}$ Moreover, the evolution of the defects with the thermal treatments could be influenced by this order because of the different mobility of $\mathrm{He}$ and $\mathrm{H}$ : $\mathrm{He}$ is more mobile and tends to agglomerate, while $\mathrm{H}$ diffusion is limited by its trapping into defects.

In this work we present a study of defects produced in $\mathrm{Si}$ coimplanted by $\mathrm{He}^{+}+\mathrm{H}^{+}$by means of two complementary techniques: transmission electron microscopy (TEM) in both cross section and plan view and DP-PAS. The formation and the evolution with heat treatments of extended defects were followed by TEM measurements. DP-PAS was used to detect vacancies, vacancy clusters, and their decorations. We have focused our attention on the formation and the evolution of the different type of defects producing the blisters.

\section{EXPERIMENTAL}

\section{A. Samples}

High purity $p$-type (100) silicon wafers $(1.7-2.5 \Omega \mathrm{cm})$, Czochralski grown, were implanted at room temperature with $\mathrm{He}^{+}$ions at $30 \mathrm{keV}$ with a dose of $1 \times 10^{16}$ ions $/ \mathrm{cm}^{-2}$ and successively with $\mathrm{H}^{+}$ions at $24 \mathrm{keV}$ with a dose of 1 $\times 10^{16}$ ions $/ \mathrm{cm}^{-2}$. The two implantations were carried out in the same operative condition and without breaking the vacuum. The density of the beam current was about $8 \mu \mathrm{A} \mathrm{cm}^{-2}$ and the sample holder, kept near room temperature, was tilted by $7^{\circ}$ to reduce channeling effects. The samples, $1 \mathrm{~cm} \times 1 \mathrm{~cm}$, were isochronally annealed in vacuum for $2 \mathrm{~h}$ in steps of $100{ }^{\circ} \mathrm{C}$ in the $100-900{ }^{\circ} \mathrm{C}$ temperature range. The pressure during $2 \mathrm{~h}$ annealing at $900{ }^{\circ} \mathrm{C}$, the most extreme condition, was between $1 \times 10^{-6}$ and 5 $\times 10^{-6}$ mbar.

The $\mathrm{He}$ and $\mathrm{H}$ depth distributions, as measured by elastic recoil detection, were found to be peaked at 270 and $290 \mathrm{~nm}$, respectively. The FWHM (full width at half maximum) of the two distributions was about $190 \mathrm{~nm} .{ }^{31}$ Similar samples, produced in the same conditions were characterized as a function of the isochronal heat treatments by various analytical techniques: backscattering in channeling conditions (RBS-C) to detect damage distribution, elastic recoil detection (ERD) to measure the helium and hydrogen content, atomic force microscopy (AFM) to analyze the surface morphology. The results are reported in Ref. 31 . At $400{ }^{\circ} \mathrm{C}$ about $\frac{1}{4}$ of He is out diffused, its distribution becomes narrower (about $70 \mathrm{~nm}$ FWHM) and He accumulates around $280 \mathrm{~nm}$. Annealing at a higher temperature produces a continuous loss of He up to $900{ }^{\circ} \mathrm{C}$ where $\mathrm{He}$ results completely desorbed. The shape of $\mathrm{H}$ distribution does not change with the thermal treatments but heating at temperatures higher than $300{ }^{\circ} \mathrm{C}$ produces a continuous loss of $\mathrm{H}$. At $900{ }^{\circ} \mathrm{C}$ also $\mathrm{H}$ results completely desorbed.

\section{B. DP-PAS measurements}

The DP-PAS measurements were carried out with an electrostatic slow positron beam tunable in the $0.05-25 \mathrm{keV}$ en- 
ergy range. ${ }^{32}$ With these energies a layer from 1 to about $3000 \mathrm{~nm}$ can be sampled. The mean positron implantation depth $\bar{z}$ is related to the positron implantation energy $E$ through the equation $\bar{z}=(40 / \rho) E^{1.6}$ with $\bar{z}$ in nanometers when density $\rho$ and energy $E$ are expressed in grams per cubic centimeter and keV, respectively. ${ }^{33}$ To depth profiling the open volume defects, the Doppler broadening spectroscopy (DBS) was employed. ${ }^{33,34}$ The Doppler broadening of the $511 \mathrm{keV}$ positron-electron annihilation line $G\left(E, E_{\gamma}\right)$, where $E_{\gamma}$ is the energy of the annihilation gamma ray, was measured as a function of the positron implantation energy $E$. For these measurements a high-purity Ge detector (resolution of $1.2 \mathrm{keV}$ at $511 \mathrm{keV}$ with $6 \mu$ s shaping time) was used. The annihilation spectra were acquired with a microspectra method and stabilized by a software procedure. ${ }^{19}$ The spectra were characterized by the so-called shape parameter $S,{ }^{33}$ defined as the ratio of the counts in a central area $\left(\left|511-E_{\gamma}\right| \leqslant 0.85 \mathrm{keV}\right)$ of the $G\left(E, E_{\gamma}\right)$ line and the total area $\left(\left|511-E_{\gamma}\right| \leqslant 4.25 \mathrm{keV}\right)$ of $G\left(E, E_{\gamma}\right)$. In parenthesis our choice of the energy windows is reported. The Doppler broadening $\Delta E$ of $G\left(E, E_{\gamma}\right)$ is related to the electronpositron annihilating pair momentum component $p_{L}$, in the detector direction, by the relation $\Delta E=p_{L} c / 2$ (where $c$ is the light velocity). $S$ parameter represent the fractions of positrons annihilating with low-momentum electrons; our energy window corresponds to pair momentum in the $0 \leqslant\left|p_{L}\right|$ $\leqslant 3.3 \times 10^{-3} m_{\mathrm{o}} \mathrm{c}$ range ( $m_{\mathrm{o}}$ is the rest mass of electron). The $S$ parameter has been measured with a statistical error of $0.1 \%$ (more than $2.5 \times 10^{5}$ counts in each annihilation spectrum). Positrons injected in a solid thermalize in a few picoseconds then, after a diffusive path, are favorably trapped in a vacancy or open volume site where the ion density is reduced. Trapped positrons annihilate mainly with low momentum electrons of the external part of the atoms, and contribute to an increase of the $S$ parameter values. The present $S$ vs $E$ (depth) curves were normalized to the $S i$ bulk value $S_{b}\left(S_{n}=S / S_{b}\right)$.

In order to analyze more thoroughly the structure of open volume defects we also carried out coincidence Doppler broadening (CDB) measurements in a few interesting samples. Such measurements enable one to study the high momentum region $\left(5 \times 10^{-3} m_{\mathrm{o}} \mathrm{c} \leqslant p_{L} \leqslant 40 \times 10^{-3} m_{\mathrm{o}} \mathrm{c}\right)$ of $G\left(E, E_{\gamma}\right)$, corresponding to annihilation with core electrons. The annihilation with core electrons is a fingerprint of the chemical elements and gives information on the decoration of open volume defects. ${ }^{35-37}$ For coincidence measurements, two high purity germanium detectors (HPGe) $45 \%$ efficiency, $1.4 \mathrm{keV}$ resolution at $511 \mathrm{keV}$, in a $180^{\circ}$ configuration were used. The information about the environment of the open volume defects are highlighted by peaks or valleys in ratio curves constructed as the ratio between $G\left(E, E_{\gamma}\right)$ line measured in the sample under investigation and a reference line $G_{b}\left(E_{\gamma}\right)$, measured in bulk Si, i.e., at high positron implantation energies. ${ }^{7,8,36-38}$

\section{TEM measurements}

TEM analyses were performed on a Jeol JEM 2010 microscope (point resolution $0.19 \mathrm{~nm}$ ) equipped with a GATAN
Imaging Filter (GIF®200). Plan and cross section TEM samples were prepared by mechanical lapping to $20 \mu \mathrm{m}$ of residual thickness and $\mathrm{Ar}^{+}(4 \mathrm{keV})$ low current milling down to perforation. Energy Filtered Bright Field Images in zero loss mode, were recorded with an energy window of $15 \mathrm{eV}$.

\section{RESULT}

\section{A. TEM results}

Two terms will be used in the following sections of this paper: (a) bubbles refer to defects with nanosize dimension filled or partially filled with implanted species, (b) cavities refer to empty defects with nanosize dimensions.

Defects such as cavities or bubbles are characterized by lower electro-optic density than $\mathrm{Si}$ matrix and they can be detected by out-of-focus imaging.

\section{As-implanted sample}

In Fig. 1(a) cross section image of the as implanted sample shows a defective layer $80 \mathrm{~nm}$ wide at a mean depth of $280 \mathrm{~nm}$. This defective layer is formed by aggregates of small bubbles having a core parallel to the sample surface with high aspect ratio (platelets). Platelets are surrounded by a strong strain field, as indicated by elliptical contrast fringes.

\section{From $100{ }^{\circ} \mathrm{C}$ to $700{ }^{\circ} \mathrm{C}$ thermal treatments}

All the phenomena observed by TEM in the samples heat treated in the $100-700{ }^{\circ} \mathrm{C}$; temperature range are centered around $280 \mathrm{~nm}$ depth in a layer about $80 \mathrm{~nm}$ wide.

Thermal annealing in the $100-600{ }^{\circ} \mathrm{C}$ temperature range produces the progressive coalescence of different platelets. The cross section view presented in Fig. 1(b) for a sample annealed at $500{ }^{\circ} \mathrm{C}$, shows how platelets tend to bend and to group one with the other, increasing their thickness and length. A strong strain field is still detected around the defects.

In Fig. 2, a plan view of sample annealed at $700{ }^{\circ} \mathrm{C}$ is shown. At this temperature the implanted species trapped inside the platelet cores can effuse because of their high mobility; this phenomenon produces a great instability in platelet structures that begin to resemble smaller bubbles in the surrounding volume giving rise to big cavities as in Fig. 2. Such a temperature marks the transition from strongly strained platelets to a planetarylike structure characterized by a weaker strain field and formed by a central cavity without appreciable strain field contrast, surrounded by bubbles of different sizes. Smaller bubbles have still an almost spherical shape and are tens $\mathrm{nm}$ wide, while medium bubbles can reach the diameter of $100 \mathrm{~nm}$ and show nonequilibrium facets; the central cavity occupies a wide area with a diameter of about $1 \mu \mathrm{m}$ and its irregular shape is due to the fact that platelets lie at different depth. A detailed cross section analysis of similar structures formed after annealing at about $600{ }^{\circ} \mathrm{C}$ of He implanted samples is presented in Ref. 39. The nonequilibrium shape of the defects, combined with the independent information on the implanted species 

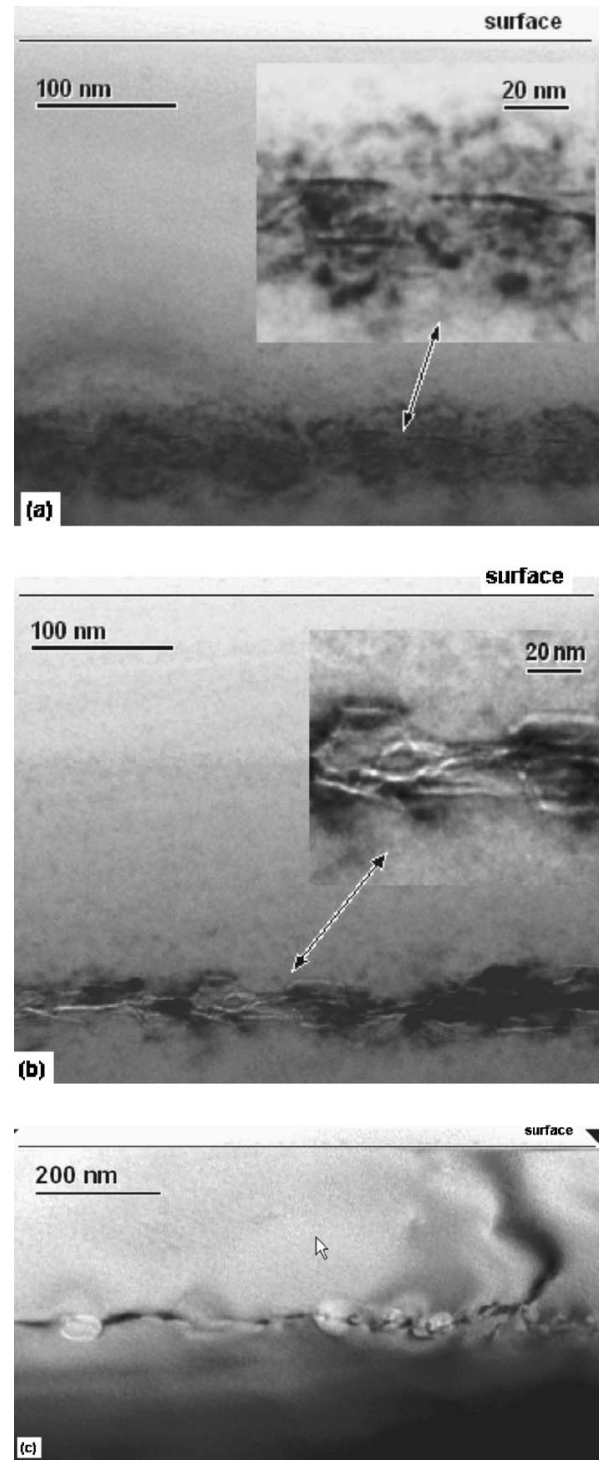

FIG. 1. (a) Cross section image of the as implanted sample. (b) Cross section image of the sample thermal treated at $500{ }^{\circ} \mathrm{C}$. (c) Cross section image of the sample thermal treated at $800{ }^{\circ} \mathrm{C}$.

concentration, ${ }^{31}$ allows us to infer that cavities are still decorated with gas atoms.

\section{3. $800-900{ }^{\circ} \mathrm{C}$ thermal treatments}

At $800-900{ }^{\circ} \mathrm{C}$, the platelets disappear and at $900{ }^{\circ} \mathrm{C}$ there is an attenuation of the strain field [Fig. 1(c)]. The samples present blisters on the surface, some microns wide, formed by crystalline lamellae suspended over buried empty cavities. Some empty cavities have an elongated shape up to $4 \mu \mathrm{m}$ long and a hundred nanometers wide. Smaller cavities of nanometer size are dispersed in the interblister space (see also Fig. 3 in Ref. 40). Some exfoliated layers are also present.

\section{B. DP-PAS results: measurements and analysis}

\section{Doppler broadening measurements}

The DP-PAS measurements carried out with the DBS technique are presented in Fig. 3. In this figure the $S_{n}$ param-

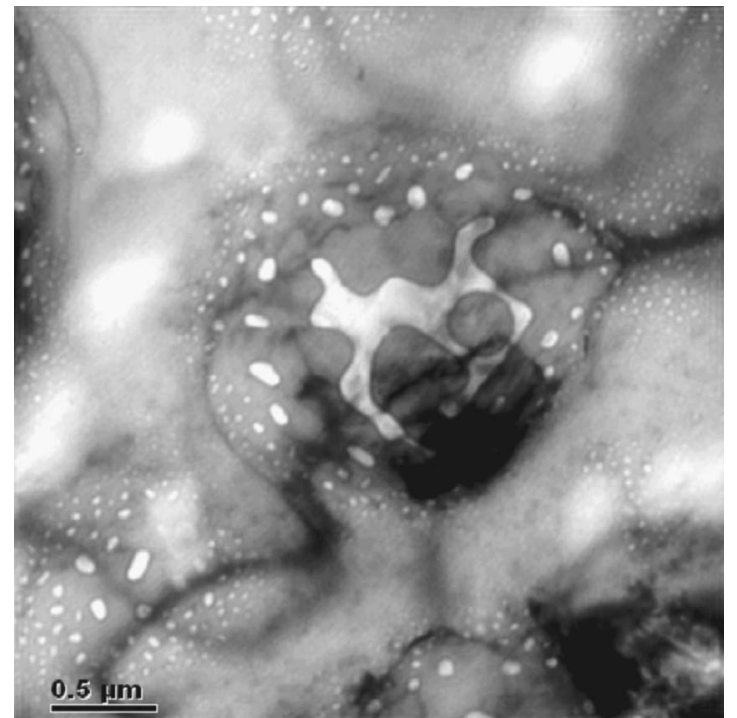

FIG. 2. Plan view of the sample thermal treated at $700{ }^{\circ} \mathrm{C}$.

eter vs $E$ and vs mean positron implantation depth $\bar{z}$ of the as-deposited and thermally treated samples is shown. A visual inspection of the experimental data indicates that all the measured $S_{n}(E)$ values start from a $S_{n}$ value around 0.92 at the sample surface, then increase to a maximum and decrease to the $S_{n}$ value of the bulk Si. The position of the maximum is around $100 \mathrm{~nm}$ in the as-implanted samples; it moves to shallower values when the samples are heated at 100 and $200{ }^{\circ} \mathrm{C}$ [Fig. 3(a)]. The height in the maximum of the $S_{n}(E)$ curves decreases up to $200{ }^{\circ} \mathrm{C}$. From $300{ }^{\circ} \mathrm{C}$ and up, the maximum moves at increasing depths. Up to $600{ }^{\circ} \mathrm{C}$ also the height of the maximum increases [Figs. 3(b) and 3(c)]; from $700{ }^{\circ} \mathrm{C}$ the maximum value decreases again and its position moves towards $300 \mathrm{~nm}$ [Fig. 3(c)].

The shape of the $S_{n}(E)$ curves contains more information that those outlined above. In fact, due to the positron implantation profile ${ }^{33,34} P(z, E)=-\frac{d}{d z} \exp \left[-\left(\frac{z}{z_{0}}\right)^{1.9}\right]$ (with $z_{0}=1.127$ $\bar{z})$ and the positron diffusion after thermalization, the $S(E)$ measured value at each energy $E$ is a linear combination of the following terms:

$$
S(E)=S_{S} f_{s}(E)+S_{b} f_{b}(E)+\sum_{i} S_{d i} f_{d i}(E)
$$

where $f_{s}(E), f_{b}(E), f_{d i}(E)$ are the positron annihilation probabilities at the surface, in the bulk, and in the different defects that trap positrons. $S_{s}, S_{b}$, and $S_{d i}$ are the characteristic values of $S$ for positron annihilating at the surface, in the bulk and into the different defects, respectively.

A fitting procedure based on the positron diffusion model must be applied to extract quantitatively the physical parameters related to the defect distributions and the $S_{d i}$ values that characterize the type of positron traps. For details on the adopted model the reader is referred to Refs. 14, 19, and 34. Here we only outline the main points of the adopted fitting procedure. In Eq. (1) the unknown parameters are the annihilation probabilities $f$ and the characteristic values $S_{d i}, S_{b}$, and $S_{s}$ are the asymptotic values into the bulk and at the 


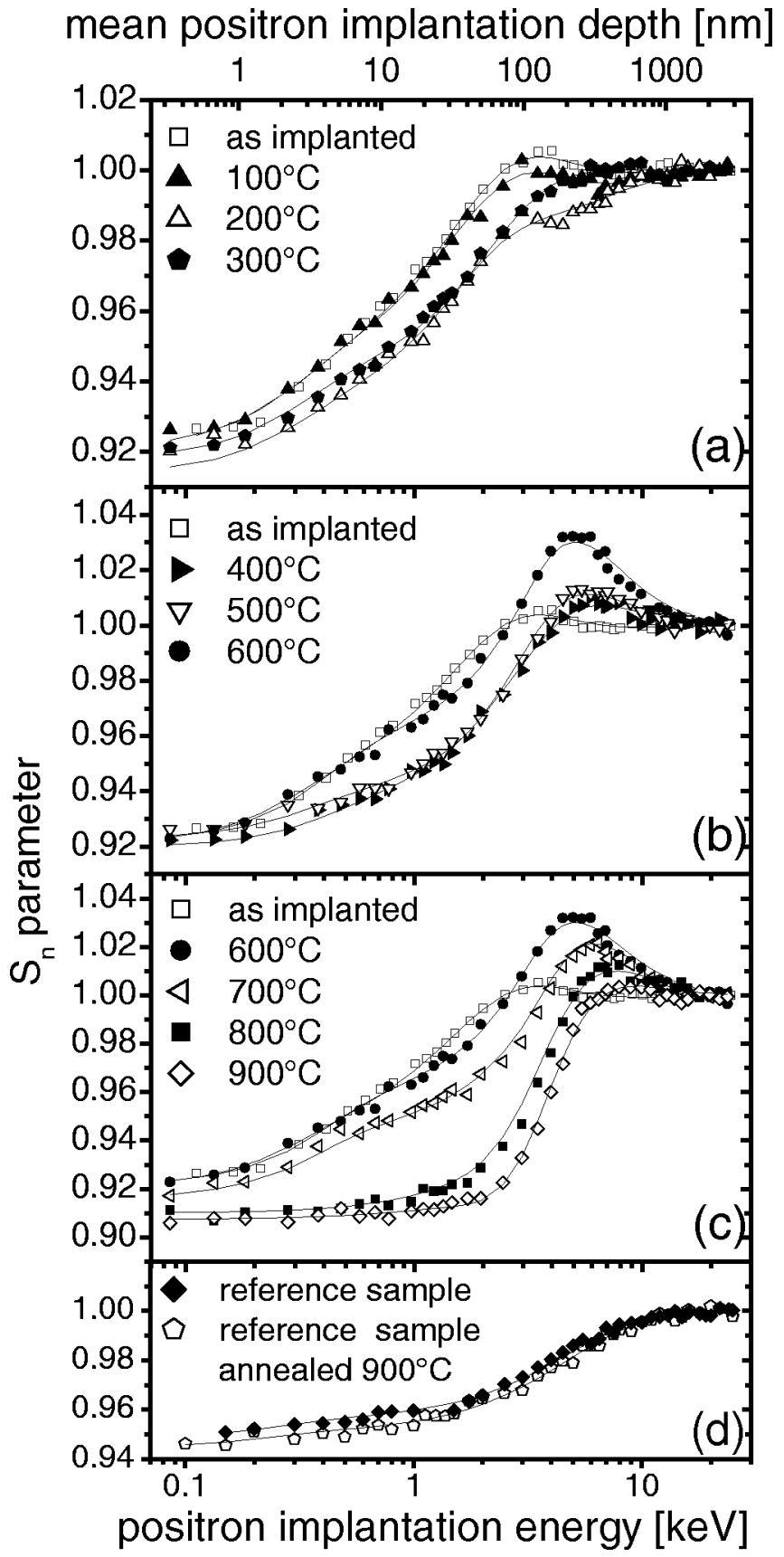

FIG. 3. Doppler broadening measurements of the positron annihilation line. $S_{n}$ parameter vs positron implantation energy (lower scale) and mean positron implantation depth (upper scale). (a) asimplanted and samples heat treated up to $300{ }^{\circ} \mathrm{C}$. (b) Samples heat treated up to $600{ }^{\circ} \mathrm{C}$. (c) Samples heat treated up to $900{ }^{\circ} \mathrm{C}$. (d) Reference c-Si virgin sample and c-Si virgin sample annealed at $900{ }^{\circ} \mathrm{C}$. The curve of the as-implanted samples is reported in (a), (b), and (c) for clarity. The continuous lines are best fit to the data with the positron diffusion model.

surface, respectively. The $f$ probabilities are related to the stationary density $n(z)$ of thermalized positrons. The density $n(z)$ is found as solution of the one-dimensional driftdiffusion equation for each positron implantation energy $E$. In particular

$$
f_{d i}=\nu_{i} \int_{0}^{\infty} C_{i}(z) n(z) d z
$$

where $\nu_{i}$ is the specific trapping rate per unit defect concentration and $C_{i}(z)$ is the density profile describing the depth distribution of the defects that trap positrons. $C_{i}(z)$ is written in a more convenient mode in terms of the function describing the defect profile $y(z)$ and the total number $N$, of defects per unit area of the sample

$$
C_{i}(z)=\frac{N}{N_{\mathrm{Si}}} y(z) .
$$

$N_{\mathrm{Si}}$ is the number of silicon atoms per unit volume, and $N$ is related to the real number of the defect of the type $d i, N_{d i}$ by the equation

$$
N_{d i}=\frac{\nu_{i}}{\nu_{d i}} N
$$

where $\nu_{d i}$ is the specific trapping rate of the defect $d i$. The specific trapping rate increases with going from the single vacancy to agglomeration of vacancies. At least for a small number of vacancies forming the vacancy cluster, the specific trapping rate of the vacancy cluster is proportional to the number $n$ of the vacancies: ${ }^{41} \nu_{\text {cluster }}=n \nu_{1 V}$, where $\nu_{1 V}$ is the specific trapping rate for a monovacancy. As specific trapping rate for a monovacancy we have assumed half of the value $\nu_{2 V}=0.8 \times 10^{15} \mathrm{~s}^{-1}$ for a neutral divacancy. ${ }^{42}$ The number of cavities was estimated by using a specific trapping rate for cavities $\nu_{\mathrm{c}}=10^{19} \mathrm{~s}^{-1}$. The specific trapping rate for cavities was extracted in Ref. 19 through the formula $\nu=c \nu_{c}$ where $\nu$ is the specific trapping rate for unit defect concentration as extracted by the DBS data, and $c$ the cavity density as estimated by TEM measurements.

In the fitting procedure the shape of the function $y(z)$ describing the defect profile is a guess. In our analysis we have chosen two different functions: a derivative of a Gaussian, Eq. (5), and a Gaussian, Eq. (6)

$$
\begin{gathered}
y(z)=\frac{1.573}{d} \frac{z}{d} \exp \left[-\left(\frac{0.887 z}{d}\right)^{2}\right], \\
y(z)=\frac{1}{\sqrt{2 \pi}} \frac{1}{\sigma} \exp \left[-\frac{(z-d)^{2}}{2 \sigma^{2}}\right] .
\end{gathered}
$$

The number $N_{d i}$, the mean depth of the defect profile $d$, the full with at half maximum $(\mathrm{FWHM}=2.34 \sigma)$ and $S_{d i}$, are the best fit parameters that are adjusted by the best-fit procedure. In the stationary diffusion equation the Si bulk annihilation rate $\lambda$ was assumed $(221 \mathrm{ps})^{-1}, D_{+}=2.0 \mathrm{~cm}^{2} / \mathrm{s}$, and the surface electric field $E=0 .{ }^{19}$ In Fig. 3(d), the $S_{n}$ vs $E$ curve of the virgin sample adopted as a reference is shown. The fit through the data is done with the above parameters. The surface silicon oxide was not removed before implantation and before the characterization with DP-PAS, TEM, and the other analytical techniques (Ref. 31). In the same figure a curve of a virgin sample annealed at $900{ }^{\circ} \mathrm{C}$ in the same condition of the implanted samples is also reported. The thermal annealing procedure in vacuum does not modify the ref- 
erence sample and do not increase the thickness of the surface oxide.

An a posteriori check indicates that with the $D_{+}$values that properly match the reference sample the depth distribution of cavities probed by positrons at $900{ }^{\circ} \mathrm{C}$ thermal annealing is in close agreement with the depth position of cavities directly observed by TEM.

The best fit curves are shown as continuous lines in Fig. 3. The results of the analysis of the $S_{n}$ vs $E$ data obtained by the best fit procedure are summarized in Fig. 4 and Table I. In Fig. 4 and Table I, for the sake of clarity, we have numbered from $d 1$ to $d 5$ the defect distributions found by best fitting the $S$ vs $E$ data. In Fig. 4, for each sample, the block diagram shows the different groups of defect distributions (different contrast) with their width at 10\% from the zero line (FWTM: full width tenth maximum). The type of defects, the $S_{d}$ parameter values characterizing the defects and the mean depth of the defect profile $d$ are reported in Table I except for distribution $d 1$, see below). When a Gaussian was used as a defect profile, the FWHM of the Gaussian distribution is also inserted in Table I.

The analysis of the $S$ vs $E$ data points out the presence of different defect types already in the as-implanted sample. Moreover, an evolution of defects, both in type as in depth, is observed with the thermal treatments. In Fig. 4 the two dashed lines around $280 \mathrm{~nm}$ mark the layer in which the extended defects are observed by TEM. This highlights that

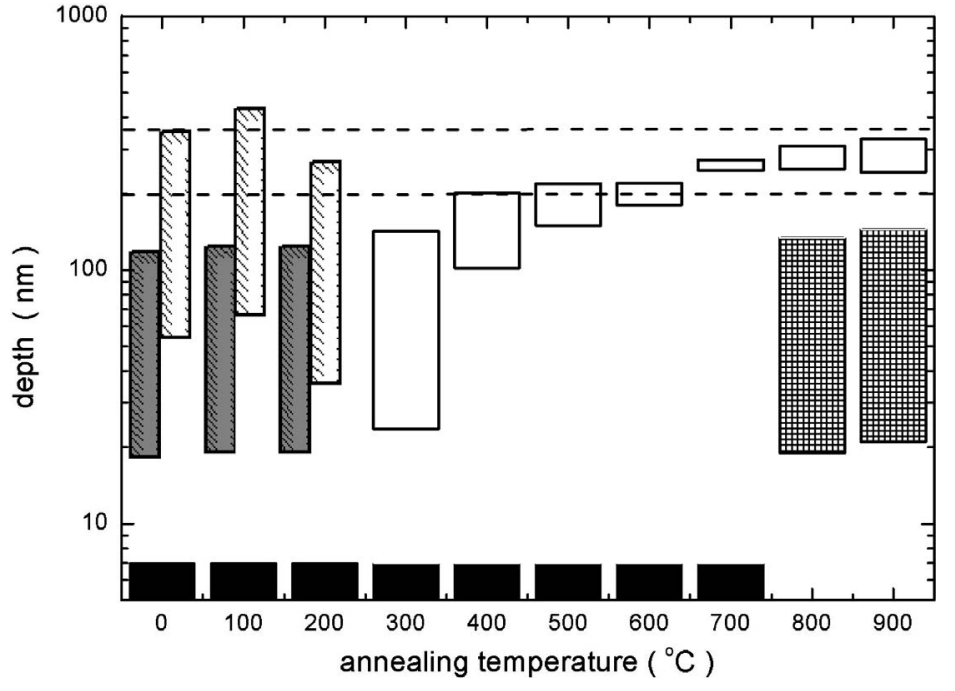

FIG. 4. Block diagram showing the different group of defects and their distribution in depth (full width at 10\%) as found by analysis of Doppler broadening measurements data. Details about defect types and their distribution are reported in Table I. Black boxes: defect distribution $d 1$. Grey boxes defect distribution $d 2$. Dashed boxes: defect distribution $d 3$. White boxes: defect distribution $d 4$. Squared boxes: defect distribution $d 5$. The two dashed lines mark the layer in which TEM analysis reveals extended defects and then nanocavities.

TABLE I. Distributions $d 2-d 5$ of the decorated vacancy clusters detected by DBS. $S_{d}: S$ values characterizing the different type of positron traps. Mean depth $d$ of the defect distributions and density $N_{d i}$ of the defects. Where a Gaussian was used as a guess for the defect distribution, the FWHM is also given. $V_{i}^{*}$ indicates defects with a free volume as a cluster of $i$ vacancies in Si. $V_{c}^{*}$ indicates nanocavities. Data about distribution $d 1$ are discussed in the text. The estimated errors on the mean depth $d$ of the defect distributions is $\pm 5 \%$ and $\pm 10 \%$ on the density $N_{d i}$.

\begin{tabular}{|c|c|c|c|c|c|c|c|c|}
\hline \multirow[b]{2}{*}{ Samples } & \multicolumn{3}{|c|}{ Distribution $d 2$} & \multirow[b]{2}{*}{$S_{d}$} & \multirow[b]{2}{*}{$\begin{array}{c}d \\
(\mathrm{~nm})\end{array}$} & \multirow[b]{2}{*}{$\begin{array}{c}N_{d i} \\
\left(\times 10^{14}\right) \\
\left(\mathrm{cm}^{-2}\right)\end{array}$} & \multicolumn{2}{|c|}{ Distribution $d 3$} \\
\hline & $S_{d}$ & $\begin{array}{c}D \\
(\mathrm{~nm})\end{array}$ & $\begin{array}{c}N_{d i} \\
\left(\times 10^{14}\right) \\
\left(\mathrm{cm}^{-2}\right)\end{array}$ & & & & $S_{d}$ & $\begin{array}{c}d \\
(\mathrm{~nm})\end{array}$ \\
\hline As-impl & 1.020 & 74 & $9.85 V_{1}^{*}$ & & & & 0.993 & 222 \\
\hline $100^{\circ} \mathrm{C}$ & 1.020 & 78 & $7.85 V_{1}^{*}$ & & & & 0.992 & 273 \\
\hline $200^{\circ} \mathrm{C}$ & 1.028 & 77 & $1.90 V_{1}^{*}$ & & & & 0.990 & 146 \\
\hline & & \multicolumn{7}{|c|}{ Distribution $d 4$} \\
\hline $300^{\circ} \mathrm{C}$ & & & & 1.036 & 93 & $0.85 V_{2}^{*}$ & & \\
\hline $400^{\circ} \mathrm{C}$ & & & & 1.058 & $\begin{array}{c}145 \\
\text { FWHM }=100\end{array}$ & $0.36 V_{4}^{*}$ & & \\
\hline $500^{\circ} \mathrm{C}$ & & & & 1.079 & $\begin{array}{c}178 \\
\text { FWHM=70 }\end{array}$ & $0.25 V_{5}^{*}$ & & \\
\hline $600^{\circ} \mathrm{C}$ & & & & 1.090 & $\begin{array}{c}194 \\
\text { FWHM=40 }\end{array}$ & $0.38 V_{6}^{*}$ & & \\
\hline $700^{\circ} \mathrm{C}$ & & & & 1.103 & $\begin{array}{c}253 \\
\text { FWHM }=25\end{array}$ & $\begin{array}{c}4.6 \times 10^{-3} \\
V_{c}^{*}\end{array}$ & & \\
\hline \multicolumn{9}{|c|}{ Distribution $d 5$} \\
\hline $800^{\circ} \mathrm{C}$ & 0.918 & 75 & - & 1.131 & $\begin{array}{c}262 \\
\text { FWHM }=58\end{array}$ & $\begin{array}{c}4.2 \times 10^{-3} \\
V_{c}^{*}\end{array}$ & & \\
\hline $900^{\circ} \mathrm{C}$ & 0.903 & 80 & - & 1.133 & $\begin{array}{c}264 \\
\text { FWHM }=86\end{array}$ & $\begin{array}{c}3.6 \times 10^{-3} \\
V_{c}^{*}\end{array}$ & & \\
\hline
\end{tabular}




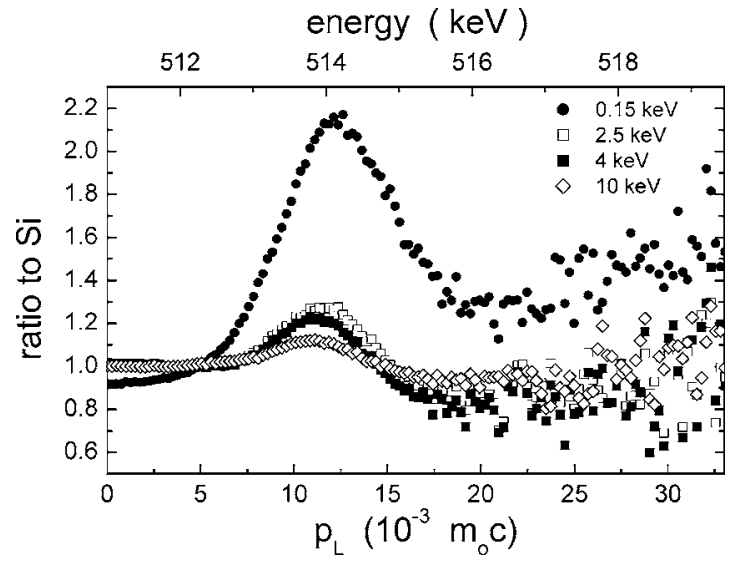

FIG. 5. Ratio of the coincidence Doppler broadening spectrum measured in the as-implanted sample at different positron implantation energies to the coincidence Doppler broadening spectrum of bulk $\mathrm{Si}$.

the two techniques are complementary in describing the different defectiveness of the analyzed samples.

\section{Doppler broadening in coincidence measurements}

In Fig. 5, as an example, the ratio curves $G\left(E, E_{\gamma}\right) / G_{b}\left(E_{\gamma}\right)$ obtained by measuring $G\left(E, E_{\gamma}\right)$ at four positron implantation energies $E$ in the as implanted sample are presented. Each curve $G\left(E, E_{\gamma}\right)$ is a linear combination of different terms

$$
G\left(E, E_{\gamma}\right)=G_{s}\left(E_{\gamma}\right) f_{s}(E)+\sum_{i} G_{d i}\left(E_{\gamma}\right) f_{d i}(E)+G_{b}\left(E_{\gamma}\right) f_{b}(E),
$$

where $G_{s}\left(E_{\gamma}\right)$ and $G_{d i}\left(E_{\gamma}\right)$ are the characteristic annihilation lines of positron annihilating at the sample surface and in the

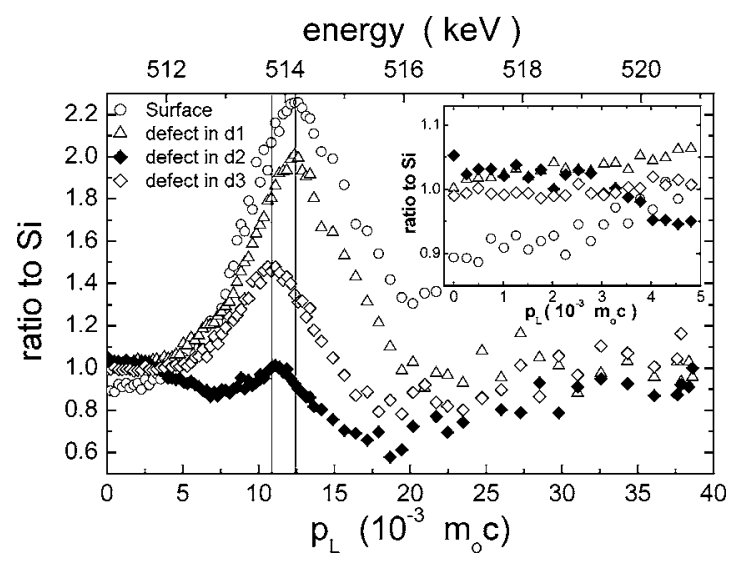

FIG. 6. Ratio of the characteristic coincidence Doppler broadening spectrum to the coincidence Doppler broadening spectrum of bulk Si for positron annihilating at the surface and into the different defects of the three defect distributions $d 1, d 2, d 3$ present in the as-implanted sample. These characteristic curves are extracted from the measured curves of Fig. 5. The vertical lines help in the identification of the position of the peaks.

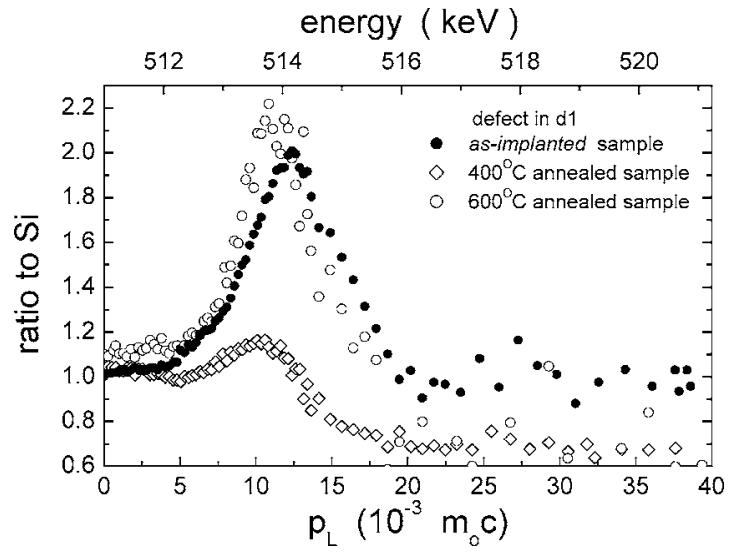

FIG. 7. Characteristic ratio curves of the defects of distribution $d 1$. Evolution of the decoration with the thermal treatment.

traps $i$. The $G_{d i}\left(E_{\gamma}\right) / G_{b}\left(E_{\gamma}\right)$ curves contain the information on the structure and the decoration of the defects that trap positrons. These curves can be obtained by solving a system formed with $i+1$ equations of the linear combination in Eq. (7). ${ }^{7,8}$ The positron fractions $f_{s}(E), f_{d i}(E), f_{b}(E)$, are extracted by modeling the $S(E)$ vs $E$ curve with the above described positron diffusion model (Fig. 3). The $G_{s}\left(E_{\gamma}\right) / G_{b}\left(E_{\gamma}\right)$, $G_{d 1}\left(E_{\gamma}\right) / G_{b}\left(E_{\gamma}\right), G_{d 2}\left(E_{\gamma}\right) / G_{b}\left(E_{\gamma}\right), G_{d 3}\left(E_{\gamma}\right) / G_{b}\left(E_{\gamma}\right)$ curves extracted for the as-implanted sample are shown in Fig. 6. A variable average smoothing was applied to the ratio curves from $E_{\gamma}=515 \mathrm{keV}$. The spectra have been normalized to unity before constructing the ratio.

The $G_{s}\left(E_{\gamma}\right) / G_{b}\left(E_{\gamma}\right)$ curve is due to positron annihilation in the native $\mathrm{SiO}_{2}$ at the $\mathrm{Si}$ surface. The characteristic peak at $E_{\gamma}=514.18 \mathrm{keV}$ due to positron annihilation with oxygen atoms ${ }^{37,38}$ is well visible. The $G_{d 1}\left(E_{\gamma}\right) / G_{b}\left(E_{\gamma}\right)$, $G_{d 2}\left(E_{\gamma}\right) / G_{b}\left(E_{\gamma}\right), G_{d 3}\left(E_{\gamma}\right) / G_{b}\left(E_{\gamma}\right)$ curves are characteristic of the defects with distribution $d 1, d 2$, and $d 3$; see Fig. 4 and Table I.

In Fig. 7 the $G_{d 1}\left(E_{\gamma}\right) / G_{b}\left(E_{\gamma}\right)$ characteristic curves, related to the defects with the distribution $d 1$ in proximity of the surface, are reported for the samples as-implanted and annealed at 400 and $600{ }^{\circ} \mathrm{C}$. In Fig. 8 the $G_{d 4}\left(E_{\gamma}\right) / G_{b}\left(E_{\gamma}\right)$ characteristic curves, related to the defect with the distribu-

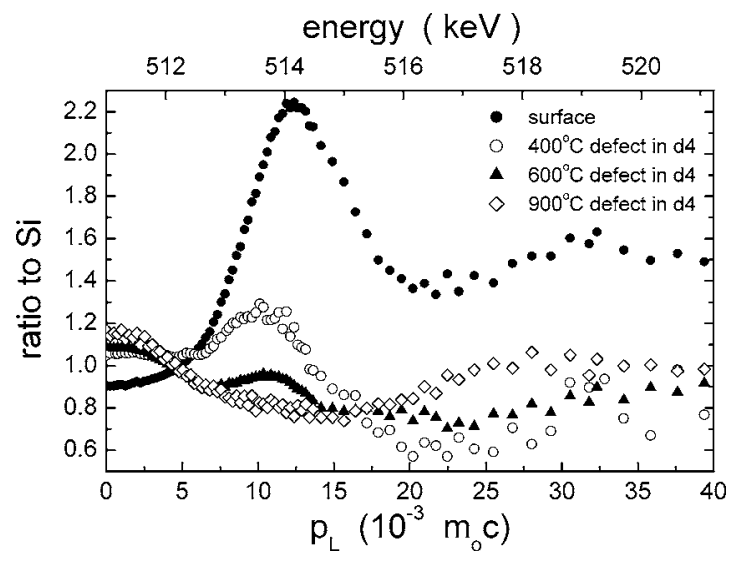

FIG. 8. Characteristic ratio curves of defects of distribution $d 4$. Evolution of the decoration with the thermal treatment. 
tion $d 4$ moving towards $280 \mathrm{~nm}$ depth, are reported for the samples heat treated at 400,600 , and $900{ }^{\circ} \mathrm{C}$. In the same figures the characteristic curves of positron annihilation in the $\mathrm{SiO}_{2}$ surface native oxide is also reported.

The following interesting features must be outlined. The peaks characterizing the defects of distributions $d 2, d 3$, and $d 4$ are all centered around $p_{L}=10.96 \mathrm{~m}_{\mathrm{o}} \mathrm{c}(513.8 \mathrm{keV})$. The peak characterizing the defect of distribution $d 1$ start from a $p_{L}=12.32 \mathrm{~m}_{\mathrm{o}} \mathrm{c}(514.15 \mathrm{keV})$ position in the as-implanted sample than it stabilizes around the $p_{L}=10.96 \mathrm{~m}_{\mathrm{o}} \mathrm{c}$ $(513.8 \mathrm{keV})$ position before disappearing at $800{ }^{\circ} \mathrm{C}$ annealing temperature. For the same defect type, the height of the peak is associated with the decoration: more decoration more intense the peak.

The identification of the defects and their decoration will be presented in the following paragraphs with reference to Table I and Figs. 4 and 6-8.

\section{DISCUSSION}

\section{A. Defects characterization}

\section{As-implanted sample}

The analysis of the DBS data allows us to distinguish three distributions of three different traps in the as-implanted sample. A distribution $d 1$, located near the surface with FWTM of $4 \mathrm{~nm}, S_{d}=1.02$ and $N_{d}=9.5 \times 10^{14} \mathrm{~cm}^{-2}$ (the data is not presented in Table I). A second one $(d 2)$ centered around $74 \mathrm{~nm}$, with $S_{d}=1.02$ and finally a distribution $d 3$ centered at $222 \mathrm{~nm}$ with an $S_{d}$ slightly lower than 1 .

The characteristic ratio curves of the defects of the three distributions are shown in Fig. 6. The peaks in the ratio curve points out the decoration of these defects. A typical ratio curve for a clean vacancy or vacancy cluster in Si would be higher than 1 below and lower than 1 above $p_{L} \cong 4$ $\times 10^{-3} \mathrm{~m}_{\mathrm{o}} \mathrm{c}$. Then, after a minimum the curve would move monotonically towards one. ${ }^{43}$ The shape of the curve of clean cavities in Fig. 8 (sample annealed at $900{ }^{\circ} \mathrm{C}$ ) follows this trend.

The thin defective layer (FWTM $4 \mathrm{~nm}$ ) at the surface, distribution $d 1$, is due to a modification of the surface during ion implantation. The surface $S_{s}$ value of 0.92 for the asimplanted and annealed samples [Figs. 3(a)-3(c)], compared with $S_{s}$ around 0.94 for the reference c-Si with native silicon oxide on the surface [Fig. 3(d)], is an indication of this modification. This modification is not due to the thermal annealing but to the implantation process. Indeed, c-Si reference sample which was not implanted and heat treated up to $900{ }^{\circ} \mathrm{C}$ does not show any meaningful change of the surface $S_{s}$ value [see Fig. 3(d)]. The defects with the distribution $d 1$ appear to be decorated by oxygen: the peak position in the ratio curve is coincident with the peak position coming from positron annihilation with oxygen atoms of the native dioxide of the surface (Fig. 6). The decoration of oxygen of the open volume defects of this layer is probably due to oxygen displaced below the surface by the impinging ions.

The decoration of defects of distributions $d 2$ and $d 3$, centered in the same position, can be ascribed to the implanted light ions $(\mathrm{H}$ and $\mathrm{He})$. As a matter of fact the distribution $d 3$ of the more decorated defects (higher peak) overlap in depth with the distribution of the implanted ions. By the above considerations we attribute the peak around $p_{L}=10.96 \mathrm{~m}_{\mathrm{o}} \mathrm{c}$ $(513.8 \mathrm{keV})$ to decoration of $\mathrm{H}$ and $\mathrm{He}$.

The $S_{d}$ value of 1.02 in c-Si corresponds to a trap with an effective volume of a monovacancy in $\mathrm{Si}^{43}$ We are not aware of calculations of momentum distribution of electronpositron pairs at vacancy clusters in c-Si stabilized, or partially saturated, by impurity elements such as $\mathrm{He}$ or $\mathrm{H}$. Therefore our assignment of the free volume of the defect to the $S_{d}$ fitted values will be done on the basis of the calculations of momentum distribution of electron-positron pairs at vacancy clusters in c-Si reported in Ref. 43. We shall indicate defects with an effective open volume of a monovacancy but decorated (or stabilized by a host species) with the $V_{1}^{*}$ symbol and similarly for cluster of $n$ vacancies $V_{n}^{*}{ }^{*}{ }^{18,19}$

The observed defects with the distribution $d 2$, with an open volume of the size of a monovacancy, are the vacancies produced by ion implantation and stabilized by $\mathrm{He}$ and $\mathrm{H}$.

The third layer of defects with $S_{d}<1$ is superimposed on the distribution of the implanted species and on the extended defect region observed by TEM, centered at $280 \mathrm{~nm}$ and $80 \mathrm{~nm}$ large (see the paragraph: TEM results). In this region, beyond the extended defects also big agglomerates of $\mathrm{H}$ and He are expected. An $S_{d}$ value less than 1.0 indicates that positrons are trapped in sites in which they annihilate preferentially with electrons of higher momentum. We can identify these defects as sites rich in $\mathrm{He}$ and $\mathrm{H}$ but not completely saturated. These positron traps must be created by the interaction of $\mathrm{H}^{+}$, the second implanted ion, with the preexisting defects produced by $\mathrm{He}^{+}$implantation. One possibility could be that $\mathrm{H}^{+}$, breaking some bonds, permits the coalescence of neighbor He clusters forming defects with less He concentration. These defects, not completely saturate, trap positrons. We have to note that positrons detect such defects also in the regions before and after the defective layer resolved by TEM [see Figs. 1(a) and 4].

Because we do not know the exact morphology of the defects with distribution $d 3$, we cannot give an estimate of the specific trapping rate $\nu_{d i}$ needed in Eq. (4) to extract the number of defects. As a consequence we have not presented any evaluation of their concentration in Table I.

It may be stressed that a contribution from possible $\mathrm{O}$ segregation to these defects can be excluded because the peak in Fig. 6 characterizing the decoration is well to the left of the typical oxygen peak.

It is interesting to compare the results, for defects in distribution $d 3$, obtained in $\mathrm{He}^{+}+\mathrm{H}^{+}$coimplanted c-Si samples with the DP-PAS findings put forward in the previous papers on He (Refs. 17, 19, and 20) and H (Refs. 13-16) implanted c-Si samples.

Open volume defects produced by light ion implantation were found to be (a) stabilized and decorated by host ions, (b) completely saturated or passivated, (c) incorporated in the clustering process of the host ions. The different possibilities can be related to the mobility of the ions and to the local density of implanted ions. The local density depends on the implanted dose and the implantation energy of the ions. Towards the projected range of the ions, where the ion density is higher, the probability of forming bigger clusters or 
saturating extended and/or point defects is higher. In $\mathrm{He}^{+}$ $\left(20 \mathrm{keV}\right.$, dose $\left.1 \times 10^{15} \mathrm{He}^{+} / \mathrm{cm}^{2}, 2 \times 10^{16} \mathrm{He}^{+} / \mathrm{cm}^{2}\right)$ and $\mathrm{H}^{+}$ (15.5 keV, dose $\left.1.6 \times 10^{16} \mathrm{H}^{+} / \mathrm{cm}^{2}\right)$ implanted samples, a complete saturation of defects near the projected range was observed by DBS. ${ }^{14,19}$ Besides, at higher implantation energy and about the same dose, DBS and PALS measurements detected defects also near the ion projected range and indicating partial defects saturation: $\mathrm{He}^{+}$implanted at $60 \mathrm{keV}$ (dose $\left.1 \times 10^{15} \mathrm{He}^{+} / \mathrm{cm}^{2}\right),{ }^{20} \mathrm{H}^{+}$implanted at $60 \mathrm{keV}$ (dose 1 $\times 10^{15} \mathrm{H}^{+} / \mathrm{cm}^{2}$ ), ${ }^{15} \mathrm{H}^{+}$implanted at $35,60,100 \mathrm{keV}$ (dose $\left.1 \times 10^{15} \mathrm{H}^{+} / \mathrm{cm}^{2}\right) .{ }^{13}$

The present results on $\mathrm{He}^{+}+\mathrm{H}^{+}$coimplanted c-Si samples, compared with the results of Refs. 14 and 19 on single implantation of $\mathrm{H}$ or $\mathrm{He}$, show the synergic effect of $\mathrm{H}$ and $\mathrm{He}$ in producing noncompletely saturated defects also at low implantation energy in spite of the same total ion dose deposited. This is probably the main difference that brings about the blistering process after annealing at high temperature.

\section{Near surface modification from $100{ }^{\circ} \mathrm{C}$ to $800^{\circ} \mathrm{C}$}

The defects in the thin defective layer (FWTM $4 \mathrm{~nm}$ ) at the surface, distribution $d 1$, do not change up to $300{ }^{\circ} \mathrm{C}$ annealing temperature. At $400{ }^{\circ} \mathrm{C}-500{ }^{\circ} \mathrm{C}$ annealing the defects have always an open volume like that of a monovacancy $\left(S_{d}=1.02\right)$ but their decoration changes. With reference to Fig. 7 we can note that at $400{ }^{\circ} \mathrm{C}$ annealing temperature the defects decoration can be attributed to some $\mathrm{H}$ and $\mathrm{He}$ that are retrapped during their out diffusion from the sample, in fact the peak position move at $p_{L}$ $=10.96 \mathrm{~m}_{\mathrm{o}} \mathrm{c}$. At 600 and $700{ }^{\circ} \mathrm{C}$ the decorated defects grown in size and present an open volume similar to that of a divacancy $\left(S_{d}=1.034\right)$. The decoration of the defects at $600{ }^{\circ} \mathrm{C}$ strongly increases and can be always attributed to $\mathrm{H}$ and $\mathrm{He}$ (peak at $p_{L}=10.96 \mathrm{~m}_{\mathrm{o}} \mathrm{c}$ in Fig. 7) that are out diffusing. The defect distribution $d 1$ located near the surface completely disappear at $800{ }^{\circ} \mathrm{C}$ (see Fig. 4).

\section{3. $100{ }^{\circ} \mathrm{C}-200{ }^{\circ} \mathrm{C}$ thermal treatments}

In the following section we present and discuss the evolution of the defects lying deeper than $20 \mathrm{~nm}$ (see Fig. 4).

Within the $100-200{ }^{\circ} \mathrm{C}$ temperature range we observe an evolution of the number of stabilized $V_{1}^{*}$ in the distribution $d 2$, without modification of the type of the observed defects. The $V_{1}^{*}$ concentration decreases by about five times going from the as-implanted to the $200{ }^{\circ} \mathrm{C}$ treated sample, while the spatial distribution remains practically unchanged.

Differently, the distribution $d 3$ moves towards the surface at $200{ }^{\circ} \mathrm{C}$ and becomes centered before the defective layer observed by TEM.

At these annealing temperatures there is no out diffusion of $\mathrm{He}$ and $\mathrm{H}$ (Refs. 19 and 31) and the observed changes must be due to the rearrangement of light ions and vacancies produced by the implantation. In particular, the decrease of $V_{1}^{*}$ is due to two possible processes: the formation of larger complexes of light ions at the expense of the open volumes and the recombination of vacancies with displaced Si atoms. The first process could be particularly dominant in the region of the extended defects as positrons are less trapped in that region after annealing at $200{ }^{\circ} \mathrm{C}$.

\section{From $300{ }^{\circ} \mathrm{C}$ to $700{ }^{\circ} \mathrm{C}$ thermal treatments}

At $300{ }^{\circ} \mathrm{C}$, the $V_{1}^{*}$ disappear and positrons are not trapped in the region of extended defects. PAS probes only one distribution of defects not overlapping with the defect observed by TEM. This indicates that the extended defects are now completely saturated by the light ions. The defects of the distribution are characterized by an $S_{d}=1.036$ value related to open volume with a divacancy character $\left(V_{2}^{*}\right)$ showing an effective increase of the open volumes stabilized by $\mathrm{He}$ and H.

The big change of the defect distribution observed by passing from 200 to $300{ }^{\circ} \mathrm{C}$ annealing temperature is directly connected to the increased mobility of $\mathrm{H}$ and $\mathrm{He}$ that starts from above $250{ }^{\circ} \mathrm{C}$ annealing temperature. ${ }^{19,31} \mathrm{H}$ starts to out diffuse without changing its distribution ${ }^{31}$ while $\mathrm{He}$ moves both toward the surface out diffusing and towards the extended defects peaking there its distribution. ${ }^{31}$ The effect of saturation of the open volumes, the increasing dimensions and the connection of platelets is so mainly to be attributed to $\mathrm{He}$.

From $400{ }^{\circ} \mathrm{C}$ to $600{ }^{\circ} \mathrm{C}$ silicon material starts to recrystallize from the surface, apart from the thin layer next to the surface. Positrons probe a distribution of defects becoming narrower with its mean depth $d$ moving towards the position of the extended defects. The increase of the $S_{d}$ values characterizing the decorated defects shows that the free open volume of such defects increases going from 400 to $600{ }^{\circ} \mathrm{C}$.

The $S_{d}=1.058$ value at $400{ }^{\circ} \mathrm{C}$ is between the $S$ values characteristic of an open volume of a trivacancy and a tetravacancy in $\mathrm{Si}^{43}$ After this thermal treatment there is probably a mixing of decorated clusters with a character of tri $\left(V_{3}^{*}\right)$ and tetra- $\left(V_{4}^{*}\right)$ vacancies. At $600{ }^{\circ} \mathrm{C}$ the $S_{d}$ value is near to that of a cluster of six vacancies $\left(V_{6}^{*}\right)$. In Fig. 8 the decoration by the $\mathrm{H}$ and $\mathrm{He}$ of the defects is directly confirmed by the peak at $p_{L}=10.96 \mathrm{~m}_{\mathrm{o}} \mathrm{c}(513.8 \mathrm{keV})$. The height of the peak decreases as the open volume of the decorated cluster increases going from 400 to $600{ }^{\circ} \mathrm{C}$. This is an indication that defect are less decorated at $600{ }^{\circ} \mathrm{C}$.

The appearance of larger decorated open volume at increasing depth and the disappearance of smaller decorated open volumes in the region towards the surface point out that $\mathrm{He}$ and $\mathrm{H}$ agglomerates are formed with increasing dimensions from the surface to the center of their distribution. The dimension of the agglomerates increases with depth being related to the local concentration of the implanted species. Increasing the annealing temperature $\mathrm{H}$ and $\mathrm{He}$ progressively diffuse from the agglomerates leaving vacancy clusters. These vacancy clusters are, however, decorated and stabilized. The decorated vacancy clusters are not mobile; their disappearing passes through their decomposition with formation of vacancies or divacancies. ${ }^{2}$ Vacancies or divacancies can recombine with displaced $\mathrm{Si}$, out diffuse or be attracted by larger $\mathrm{H}$ and $\mathrm{He}$ agglomerate increasing the size of the complex by Ostwald ripening.

The $S_{d}$ value at $700^{\circ} \mathrm{C}$ reaches the value denoting the presence of cavities with sizes also in the nanometer range. ${ }^{19}$ The distribution at $700{ }^{\circ} \mathrm{C}$ is very narrow and positioned in the region in which the big partially filled cavities seen by TEM (see Fig. 2) start to form. At higher temperature the 
smaller cavities most probably increase the size of the biggest and partially filled cavities by Ostwald ripening process.

\section{5. $800-900{ }^{\circ} \mathrm{C}$ thermal treatments}

At this temperature the samples present a strong morphological change. Atomic force microscopy (AFM) images show the presence of blisters with lateral dimensions and height in the micron range. The area fraction covered by this blisters is about $45 \%$ at $900{ }^{\circ} \mathrm{C}$ and about the $2 \%$ of the surface is exfoliated. ${ }^{31}$ On the other hand, thermal desorption and ERD measurements demonstrate that $\mathrm{He}$ and $\mathrm{H}$ are completely desorbed. ${ }^{19,28,31}$ TEM images show that under the blisters there are large and extended open volumes with the same dimension of the blisters (see also Ref. 40) and that between blisters cavities of different nanometer sizes are formed.

On the other hand, the analysis of DP-PAS data allows us to conclude that positrons probe the remaining cavities in the nanometer range as well as the internal surfaces of the extended open volumes below the blisters. The results on a similar implanted sample and heat treated at $900{ }^{\circ} \mathrm{C}$ are discussed in Ref. 8 . The distribution of the cavities, revealed by an $S_{d}$ of 1.13 , is centered around $265 \mathrm{~nm}$ and overlap with the cavities position observed by TEM.

In Fig. 8 the shape of the ratio curve of positrons annihilating into the nanocavities is characteristic of annihilation in empty cavities with clean internal surface and with no decoration. . $^{7,8}$

The low $S_{d}=0.91$ characterizing the distribution $d 5$ with $d$ around $75-80 \mathrm{~nm}$, is caused by positron trapped at the internal surface of the open volumes below the blisters. ${ }^{8}$ The very low $S_{d}$ value, characterizing the positron trapping at the internal surface of the open volumes under the blisters, was found to be due to oxygen contamination of the internal surfaces. The evidence of such decoration is the characteristic ratio curve of positron annihilating in the voids below the blister that presents a strong peak very well superimposed on the peak of the characteristic curve of positron annihilating in the native silicon dioxide of the surface. ${ }^{8}$ The depth distribution related to the $S_{d}=0.91$, reflects the distribution of the thickness of the Si material lifted by the blister formation.

\section{B. Defects evolution and blistering}

The different role of $\mathrm{H}$ and $\mathrm{He}$ in the formation of the extended defects (platelets) and finally blisters with exfoliation is well recognized. ${ }^{2,23,28-30}$ Hydrogen, which forms strong bonds with $\mathrm{Si}$ dangling bonds produced by implantation damage, has a chemical action. It decorates and passivates the internal surface of platelets helping the splitting of the two facing surfaces. On the other hand, the agglomeration of $\mathrm{He}\left(\right.$ and $\left.\mathrm{H}_{2}\right)$ in such defects produces the high internal pressure necessary to drive the growth of the blisters and the increase of the cracks leading to the exfoliation.

As regards the effects due to the order of implantation $\left(\mathrm{He}^{+}+\mathrm{H}^{+}\right.$or $\left.\mathrm{H}^{+}+\mathrm{He}^{+}\right)$, a recent comparative study of implantation at low energy ${ }^{27}$ indicates that the most efficient way to obtain blistering is to implant $\mathrm{He}^{+}$and then $\mathrm{H}^{+}$. The two main conclusions that have been reached are: (1) implantation with $\mathrm{He}^{+}$promotes the appearance of internal surfaces easily passivated by $\mathrm{H}^{+}$post implantation. He helps in their pressurizations during annealing at high temperature; (2) $\mathrm{He}^{+}$post implantation destroys the formed $\mathrm{Si}-\mathrm{H}$ structures required for the splitting process of the surfaces in the high defective region and accelerate He desorption.

Less clear is the role of the point defects and the multivacancy-He, $-\mathrm{H}$ complexes in the process going from the implantation to the blister formation. The key point is to understand whether or not and how diffusing hydrogen, helium, and vacancies in the layer between the surface and the extended defect region contribute to the formation of blisters.

Multivacancy complexes with $\mathrm{H}$ have been studied by vibrational spetroscopies (Raman and Infrared spectroscopy). ${ }^{24,27,44}$ In the stretching mode region of $\mathrm{Si}-\mathrm{H}$, from 1800 to $2300 \mathrm{~cm}^{-1}$ wave number, several discrete vibrational modes superimposed on a broad absorption band are observed. The broadband is attributed to multivacancy hydrogen complexes in the highly damaged region near the peak of the implanted species. While the discrete modes are due to $\mathrm{H}$ terminated vacancy $\left(\mathrm{VH}, \mathrm{V}_{2} \mathrm{H}, \mathrm{V}_{2} \mathrm{H}_{2}\right)$, and hydrogenated interstitials $\left(\mathrm{IH}_{2}\right)$ below and above the highly damaged region. The broadband disappears with annealing at $500{ }^{\circ} \mathrm{C}$ (the temperature at which blistering starts), together all discrete modes from 1800 to $2050 \mathrm{~cm}^{-1}$ coming from $\mathrm{VH}, \mathrm{V}_{2} \mathrm{H}, \mathrm{V}_{2} \mathrm{H}_{2}$. Conversely, a strong signal due to $\mathrm{H}$ terminated internal surfaces appears and also some modes attributed to $\mathrm{VH}_{3}, \mathrm{VH}_{4}, \mathrm{~V}_{2} \mathrm{H}_{6}$.

With positron annihilation spectroscopy we can outline a complementary view of the phenomena taking into account the following points: (a) positrons probe the effective open volume of the vacancy-decorated defects (Table I), (b) all the probed vacancies and vacancy clusters are found to be decorated except the nanocavities after annealing at $900{ }^{\circ} \mathrm{C},,^{14,19}$ (c) completely filled or completely passivated open volumes by light ions are not probed by positrons, (e) with depth profiling spatial distribution of the vacancies and vacancyclusters defects are probed (Fig. 4 and Table I). This last point allows us to follow directly the spatial evolution of the decorated open volume defects.

In Fig 4 we can distinguish three well defined annealing temperature intervals in which the phenomena are clearly different: as-implanted $200{ }^{\circ} \mathrm{C}, 300-700{ }^{\circ} \mathrm{C}, 800-900{ }^{\circ} \mathrm{C}$. The three intervals are related to the $\mathrm{H}$ and $\mathrm{He}$ out diffusion. Below $300{ }^{\circ} \mathrm{C}$ no out diffusion of the implanted species is observed..$^{29,31}$ At $800-900{ }^{\circ} \mathrm{C}$ the last out diffusion of $\mathrm{H}$ and He takes place with the exfoliation and blistering processes. In all three intervals there is diffusion of $\mathrm{H}$ (activation energy $\left.E_{a}=0.48 \mathrm{eV}\right), \mathrm{He}\left(E_{a} \cong 0.96 \mathrm{eV}\right)$ and vacancy $V\left(E_{a}\right.$ $=0.45 \mathrm{eV}) \cdot{ }^{2,45} \mathrm{H}$ can passivated vacancies and $V$ is predicted to dissociate interstitial $\mathrm{H}_{2}$ forming a complex $\mathrm{VHH}^{45}$

The main considerations are as follows.

(1) In sample implanted only with $\mathrm{He},{ }^{19} \mathrm{He}$, that like to agglomerate in $\mathrm{Si}$, forms clusters of different dimensions according its local concentration and deeper platelets. All these defects are saturated by $\mathrm{He}$ and not visible by positrons; only a near to the surface distribution of $V_{1}^{*}, V_{2}^{*}$ was observed. In the present coimplanted sample the effect of $\mathrm{H}$ implantation after $\mathrm{He}$ is revealed by the presence of defects from the sur- 
face beyond the extended defect region observed with TEM. This can be explained by a strong interaction of $\mathrm{H}$ with the preexisting damage produced by $\mathrm{He}$, in particular with the $\mathrm{Si}$ dangling bonds (bond energy of $\mathrm{Si}-\mathrm{H} 3.9 \mathrm{eV}$ ), with formation of new not completely saturated defects.

(2) At 100 and $200{ }^{\circ} \mathrm{C}$ only an internal redistribution of $\mathrm{He}$ and $\mathrm{H}$ takes place. The concentration of $V_{1}^{*}$ (the less deep distribution $d 2$ ) strongly decreases for $\mathrm{Si}-\mathrm{V}$ recombination and/or saturation by rearrangement of $\mathrm{H}$ not yet strongly bonded. At $100{ }^{\circ} \mathrm{C}$ positrons probe deeper defects (distribution $d 3$ ) showing that probably the chemical action of $\mathrm{H}$ is active also at this low annealing temperature. At $200{ }^{\circ} \mathrm{C}$ the distribution of these defects moves towards the surface. The disappearance of deeper defects can be explained by saturation due to mobile $\mathrm{He}$ and $\mathrm{H}$ in the region of their maximum concentration.

(3) From $300{ }^{\circ} \mathrm{C}$ the activation and diffusion of $\mathrm{He}, \mathrm{H}$, and vacancies start to be considerable. $\mathrm{H}$ is mainly bonded and its distribution is depleted in a uniform way. $\frac{1}{4}$ of $\mathrm{He}$ is desorbed at $400{ }^{\circ} \mathrm{C}$ but its distribution peaks in the highly defective region around $280 \mathrm{~nm}$ up to $700{ }^{\circ} \mathrm{C}$ going to increase the pressure inside the extended defects. ${ }^{31}$ The first direct effect at $300{ }^{\circ} \mathrm{C}$ is the disappearance of small vacancy such as defects $V_{1}^{*}$ (this work) and small $V$-H defects. ${ }^{24,27,44}$ From $300{ }^{\circ} \mathrm{C}$ to $700{ }^{\circ} \mathrm{C}$ (see Fig. 4) we observe (a) a progressive reduction of the region with saturated defects; (b) an increase of the free volume of defects from $V_{2}^{*}$ to $V_{6}^{*}$ and to nanocavity size; (c) a distribution of these defects becoming narrower and with its mean depth moving towards the extended defect region. This behavior can be explained by the dissociation of the smaller complex vacancy-light atoms with out diffusion of $\mathrm{H}$ and $\mathrm{He}$. The process $V_{n} V_{n-1}+V_{1}$ or $V_{n} V_{n-2}+V_{2}$ is favored ${ }^{2}$ producing fast diffusing $V$ or $V_{2}$ that can be captured by deeper defects increasing their size or recombined with $\mathrm{Si}$ interstitial to reconstruct the crystal. From $500{ }^{\circ} \mathrm{C}$ annealing temperature, the probed open volumes start to have effective free volumes larger than a pentavacancy. At $700{ }^{\circ} \mathrm{C}$ positrons are trapped in a very small region, probably they probe only the partially filled cavities at the rim of the planetary structures observed by TEM (Fig. 2) that are starting to grow. From $500{ }^{\circ} \mathrm{C}$ vibrational spectroscopy indicate the presence of $\mathrm{H}$ terminated surfaces ${ }^{24,27,44}$ pointing out that hydrogen helps in increasing the size of voids below the blisters by continuing is splitting action of facing $\mathrm{Si}$.

(4) At 800 and $900{ }^{\circ} \mathrm{C}$, trapped positrons give information on the internal surfaces of the cavities and of the voids below the blisters. ${ }^{7,8}$ The cavities present clean, nonterminated surfaces, while the voids are oxygen-decorated.

\section{CONCLUSIONS}

Careful analysis of DBS results by the positron stationary diffusion equation and Doppler broadening in coincidence measurements have permitted to identify decorated vacancylike defects in the as-implanted samples and decorated vacancy clusters in samples annealed within the $100-900{ }^{\circ} \mathrm{C}$ temperature range.

All the vacancies and multivacancies defects playing a significant role in the blistering process have been found to be associated with implanted light ions, forming with them complexes. Decorated vacancies present in as-implanted and treated samples up to $200{ }^{\circ} \mathrm{C}$ disappear after annealing at $300{ }^{\circ} \mathrm{C}$. From $300{ }^{\circ} \mathrm{C}$ decorated vacancy clusters of increasing size appear. The dynamics of the open volumes with thermal treatments gives an interesting insight into the effects that bring about the blistering process.

While infrared and Raman spectroscopy follow the evolution of the $\mathrm{H}$ bonds that is recognized to promote the splitting of internal surfaces, DP-PAS shows how the effect of this splitting is accompanied by the presence of open volumes. By comparing c-Si implanted at the same total dose $\left(2 \times 10^{16}\right.$ ions $\left./ \mathrm{cm}^{2}\right)$ with $\mathrm{He}^{+}$(Ref. 19) or $\mathrm{He}^{+}+\mathrm{H}^{+}$, it is recognized that larger vacancy-clusters start to appear in the coimplanted c-Si at lower annealing temperatures. Moreover, in the as-implanted sample with $\mathrm{He}^{+}+\mathrm{H}^{+}$, open volumes are detected at the depth of the projected ions differently than in the $\mathrm{He}^{+}$case. The presence of these latter open volume defects can be ascribed to the coalescence of neighbor He clusters during the $\mathrm{H}$ post implantation.

These results allow for a tentative conclusion that (a) the role of the post-implanted $\mathrm{H}$ in breaking and passivating silicon bond shows up also in accelerating the formation of larger cluster, (b) that the $\mathrm{H}$ induced coalescence of neighbor defects in the platelets region just during implantation is essential to obtain blistering after a high temperature treatment. The latter point is supported by the fact that in He implanted samples, only well separated nanobubbles and than nanoclean cavities are obtained after $900{ }^{\circ} \mathrm{C}$ thermal annealing.

The splitting of the internal surfaces in the platelets region is probably a continuous process activated by the diffusing He that increase the internal pressure. The platelets region becomes a sink both of diffusing $\mathrm{He}$, out diffusing vacancies and divacancies produced in the dissociation of vacancy cluster at the highest annealing temperatures (above $\left.600{ }^{\circ} \mathrm{C}\right)$.

\section{ACKNOWLEDGMENTS}

This work was partially supported by the Ministero dell'Università e della Ricerca Scientifica e Tecnologica (MURST). C.M. and S.M. thank Provincia Autonoma di Trento for financial support. 
*Present address: IFIMAT and CONICET, Facultad de Ciencias Exactas, UNICEN, Pinto 399, B7000GHG Tandil, Argentina.

'Present address: Institute of Physics, University of Nicolaus Copernicus, 87600 Toruń, Poland.

Flectronic address: BRUSA@science.unitn.it

${ }^{1}$ M. Alatalo, M. J. Puska, and R. M. Nieminen, Phys. Rev. B 46, 12806 (1992).

${ }^{2}$ C. F. Cerofolini, F. Corni, S. Frabboni, C. Nobili, G. Ottaviani, and R. Tonini, Mater. Sci. Eng., R. 27, 1 (2000).

${ }^{3}$ S. Mäkinen, H. Rajainmäki, and S. Linderoth, Phys. Rev. B 44, 5510 (1991).

${ }^{4}$ J. Pearton, J. W. Corbett, and M. Stavola, Hydrogen in Crystalline Semiconductors (Springer, Berlin, 1992).

${ }^{5}$ J. Grisolia, F. Cristiano, G. Ben Assayag, and A. Claverie, Nucl. Instrum. Methods Phys. Res. B 178, 160 (2001).

${ }^{6}$ J. H. Evans, A. Van Veen, and C. C. Griffioen, Nucl. Instrum. Methods Phys. Res. B 28, 360 (1987).

${ }^{7}$ R. S. Brusa, C. Macchi, S. Mariazzi, G. P. Karwasz, W. Egger, P. Sperr, and G. Kögel, Phys. Rev. B 71, 245320 (2005).

${ }^{8}$ R. S. Brusa, C. Macchi, S. Mariazzi, G. P. Karwasz, W. Egger, P. Sperr, and G. Kögel, Appl. Phys. Lett. 88, 011920 (2006).

${ }^{9}$ D. A. Brett, G. de M. Azevedo, D. J. Liewellyn, and M. C. Ridgway, Appl. Phys. Lett. 83, 946 (2003).

${ }^{10}$ M. Bruel, Electron. Lett. 31, 1201 (1995).

${ }^{11}$ C. H. Yun, N. Quitoriano, and N. W. Cheung, Appl. Phys. Lett. 82, 1544 (2003).

${ }^{12}$ C. Maleville and C. Mazuré, Solid-State Electron. 48, 1055 (2004).

${ }^{13}$ J. Keinonen, M. Hautala, E. Rauhala, V. Karttunen, A. Kuronen, J. Räisänen, J. Lahtinen, A. Vehanen, E. Punkka, and P. Hautojärvi, Phys. Rev. B 37, 8269 (1988).

${ }^{14}$ R. S. Brusa, M. Duarte Naia, A. Zecca, C. Nobili, G. Ottaviani, R. Tonini, and A. Dupasquier, Phys. Rev. B 49, 7271 (1994).

${ }^{15}$ M. Fujinami, R. Suzuki, T. Ohdaira, and T. Mikado, Phys. Rev. B 58, 12559 (1998).

${ }^{16}$ R. A. Hakvoort, A. van Veen, P. E. Mijnarends, and H. Schut, Appl. Surf. Sci. 85, 271 (1995).

${ }^{17}$ M. Zhang, C. Lin, H. Weng, R. Scholz, and U. Gösele, Thin Solid Films 333, 245 (1998).

${ }^{18}$ R. S. Brusa, G. P. Karwasz, N. Tiengo, A. Zecca, F. Corni, G. Calzolari, and C. Nobili, J. Appl. Phys. 85, 2390 (1999).

${ }^{19}$ R. S. Brusa, G. P. Karwasz, N. Tiengo, A. Zecca, F. Corni, R. Tonini, and G. Ottaviani, Phys. Rev. B 61, 10154 (2000).

${ }^{20}$ M. Fujinami, T. Miyagoe, T. Sawada, R. Suzuki, T. Ohdaira, and T. Akahane, Phys. Rev. B 68, 165332 (2003).

${ }^{21}$ R. Krause-Rehberg and H. S. Leipner, Positron Annihilation in Semiconductors, Defect Studies, Springer Series in Solid State Science (Springler-Verlag, Berlin Heidelberg, 1999).

${ }^{22}$ J. L. Hastings, S. K. Estreicher, and P. A. Fedders, Phys. Rev. B 56, 10215 (1997).

${ }^{23}$ A. Agarwal, T. E. Haynes, V. C. Venezia, O. W. Holland, and D.
J. Eaglesham, Appl. Phys. Lett. 72, 1086 (1998).

${ }^{24}$ M. K. Weldon, M. Collot, Y. J. Chabal, V. C. Venezia, A. Agarwal, T. E. Haynes, T. E. Eaglesham, S. B. Christman, and E. E. Chaban, Appl. Phys. Lett. 73, 3721 (1998).

${ }^{25}$ C. Qian, B. Terreault, and S. C. Gujrathi, Nucl. Instrum. Methods Phys. Res. B 175-177, 711 (2001).

${ }^{26}$ I. Radu, I. Szafraniak, R. Shol, M. Alexe, and U. Gösele, J. Appl. Phys. 94, 7820 (2003).

${ }^{27}$ O. Moutanabbir and B. Terreault, Appl. Phys. Lett. 86, 051906 (2005).

${ }^{28}$ G. F. Cerofolini, G. Calzolari, F. Corni, C. Nobili, G. Ottaviani, and R. Tonini, Mater. Sci. Eng., B 71, 196 (2000).

${ }^{29}$ F. Corni, C. Nobili, R. Tonini, G. Ottaviani, and M. Tonelli, Appl. Phys. Lett. 78, 2870 (2001).

${ }^{30}$ Xinzhong Duo, Weili Liu, Miao Zhang, Lianwei Wang, Chenglu Lin, M. Okuyama, M. Noda, Wing-Yiu Cheung, S. P. Wong, Paul K. Chu, Peigang Hu, S. X. Wang, and L. M. Wang, J. Appl. Phys. 90, 3780 (2001).

${ }^{31}$ R. Tonini, F. Corni, C. Nobili, G. Ottaviani, F. Cazzaniga, and G. Queirolo, Solid State Phenom. 82-84, 291 (2002).

${ }^{32}$ A. Zecca, M. Bettonte, J. Paridaens, G. P. Karwasz, and R. S. Brusa, Meas. Sci. Technol. 9, 1 (1998).

${ }^{33}$ P. Asoka-Kumar, K. G. Lynn, and D. O. Welch, J. Appl. Phys. 76, 4935 (1994).

${ }^{34}$ A. Dupasquier and G. Ottaviani, in Positron Spectroscopy of Solids, edited by A. Dupasquier and A. P. Mills, Jr. (North Holland, Amsterdam, 1995), p. 491.

${ }^{35}$ M. Alatalo, H. Kauppinen, K. Saarinen, M. J. Puska, J. Makinen, P. Hautojarvi, and R. M. Nieminen, Phys. Rev. B 51, 4176 (1995).

${ }^{36}$ P. Asoka-Kumar, M. Alatalo, V. J. Ghosh, A. C. Kruseman, B. Nielsen, and K. G. Lynn, Phys. Rev. Lett. 77, 2097 (1996).

${ }^{37}$ S. Szpala, P. Asoka-Kumar, B. Nielsen, J. P. Peng, S. Hayakawa, K. G. Lynn, and H. -J. Gossmann, Phys. Rev. B 54, 4722 (1996).

${ }^{38}$ R. S. Brusa, W. Deng, G. P. Karwasz, A. Zecca, and D. Pliszka, Appl. Phys. Lett. 79, 149 (2001).

${ }^{39}$ S. Frabboni, F. Corni, C. Nobili, R. Tonini, and G. Ottaviani, Phys. Rev. B 69, 165209 (2004).

${ }^{40}$ S. Frabbroni, G. C. Gazzandi, L. Felisari, R. Tonini, F. Corni, and G. Ottaviani, Appl. Phys. Lett. 85, 1683 (2004).

${ }^{41}$ R. M. Nieminen and J. Laakkonen, Appl. Phys. 20, 181 (1979).

${ }^{42}$ A. Kawasuso, M. Hasegawa, M. Suezawa, S. Yamaguchi, and K. Sumino, Jpn. J. Appl. Phys., Part 1 34, 2197 (1995).

${ }^{43}$ M. Hakala, M. J. Puska, and R. M. Nieminen, Phys. Rev. B 57, 7621 (1998).

${ }^{44}$ Y. J. Chabal, M. K. Weldon, Y. Caudano, B. B. Stefanov, and K. Raghavachari, Physica B 273-274, 152 (1999).

${ }^{45}$ S. K. Estreicher, J. L. Hastings, and P. A. Fedders, Phys. Rev. B 57, R12663 (1998). 